\title{
Integrated Literature Review of Information Technology Leadership in Higher Education: Implications for Total Quality Management
}

\author{
Louis Hickman, $\mathrm{PhD}$ \\ Email:1chickma@purdue.edu \\ Mesut Akdere, $\mathrm{PhD}$ \\ Email: makdere@purdue.edu
}

Department of Technology Leadership \& Innovation, Purdue University

\begin{abstract}
Purpose: The current shortage of highly skilled employees across the country continues to be a concern for our higher education (HE) institutions. Information technology (IT) is used in a variety of ways to expand the reach of education, from distance education, simulation technology, Massively Open Online Courses (MOOCs), and more. Additionally, public HE institutions face flat and decreasing funding. IT departments are responsible for identifying transformational change opportunities, implementing technologies that expand the reach of our universities, and operating efficiently with flat funding. Therefore, identifying effective IT leadership practices to enable change and reduce costs is vital to success for modern HE institutions.
\end{abstract}

Methodology: This paper uses a literature review to identify leadership necessary for modern $\mathrm{HE}$ in general and for IT in particular. Utilizing a literature review enables the identification of both what has been accomplished in research, but also, the gap in research that is yet to be completed on these topics.

Findings: Overall, the environments of $\mathrm{HE}$ institutions are not conducive to innovation and transformational change. Leadership is an important enabler of innovative environments, and contemporary leadership theories like transformational leadership can help create IT-enabled transformational change in HE.

Value: HE institutions must find ways to adapt more quickly to the rapidly changing environment of the $21^{\text {st }}$ century. Leaders in IT are uniquely positioned because they have both IT and HE knowledge, enabling them, when effective, to be invaluable partners as HE institutions figure out a way forward in the rapidly changing world.

Keywords: Information Technology, higher education, Leadership, Total Quality Management Paper Type: Conference Paper 


\section{Introduction}

Leadership is widely recognized as the most important element in Total Quality Management (TQM) success. Information technology (IT) is similarly important because it helps to generate the information for making data-driven quality decisions and for managing and updating business processes. Leadership in the IT context can be essential for TQM success. IT leaders are uniquely situated: their work is poorly understood by the much of the university, but that work can be vital to establishing and maintaining competitive advantage (Bhatt et al., 2005). Business knowledge is one the most widely studied antecedents to IT value generation (c.f. Reich \& Benbasat, 2000). In higher education (HE) context, business knowledge means that IT leaders must understand how to drive both faculty and administrative success. With adequate business knowledge, IT leaders have the potential to be partners who understand the levers of the wider university and can collaborate on projects that increase the efficiency of the university.

Of Deming's 14 points for TQM (Kanji, 1990), IT leadership is, by nature, directly involved in instituting leadership, driving out fear, and breaking down barriers. Collaboration and communication are necessary for any IT solutions to benefit the institution. IT continues to increase in importance in $\mathrm{HE}$ as universities expand their use of MOOCs, simulation technology, big data, and distance education. Additionally, many efficiency gains in HE processes are due to IT systems eliminating existing bureaucratic, labor-driven job processes, replacing them with innovative lean systems. Considering how important leadership is for both TQM and IT, the funding challenges facing our HE institutions, and general societal upheaval, the leadership behaviors that demonstrate a commitment to quality and an ability to enable technological change are vital for the future success of HE.

\subsection{Higher Education Leadership}

The future of $\mathrm{HE}$ is considered a part of global competitiveness as emerging economic powers increase their investment in HE. As such, it has been suggested that the future of HE in the U.S. is reliant on leadership that enables productive and change-capable organizational cultures (Full \& Scott, 2009). The HE leadership research has missed opportunities by failing to research how leadership can create change, provide organizational direction, and support organizational effectiveness (Kezar et al., 2006). One contributor to this shortcoming is that public HE faces governance barriers to change due to public oversight that may resist change (Leih \& Teece, 2016). Adaptive, change-oriented organizational cultures cannot be created in a traditional, hierarchical fashion focused on management. Rather, a collective, collaborative, and teamoriented style of leadership has become increasingly necessary as the challenges faced by HE have increased (Kezar et al., 2006).

The emphasis on collaboration is important because the problems HE faces today cannot be solved by one or two persons. Previously, funding was expected to continuously increase together with tax revenues. Today, tax revenues are flat in many states while, simultaneously, more students than ever are served by public HE. HE leaders must pull together stakeholders from both inside and outside of their institutions. Simply pulling together a group of people with different agendas, perceptions, and skills can be key for transformational change in HE (Padró, 2010). Succeeding in bringing together diverse interests is likely to require social capital (Bolden et al., 2008), which is developed by creating connections with the leadership distributed throughout the institution. Voluntary coordination and collaboration with stakeholders has been 
proposed as the solution to the IT-business gap because it develops trusting relationships and improves organizational agility (Hickman \& Akdere 2017). Our attention now turns to how IT is positioned to tackle the challenges facing HE leadership.

\subsection{IT Leadership}

Transformational leadership (TL) is comprised of the four I's: idealized influence, inspirational motivation, individualized consideration, and intellectual stimulation (Bass \& Avolio, 1990). TL is one of the most widely explored leadership types (Day et al., 2014), and it is the most widely studied leadership type in the IT context. TL is especially important in gaining employee commitment in the non-profit context (Rowold et al., 2014). Leadership, rather than management, is especially important for IT since expertise is distributed and requires collaboration to combine into valuable solutions, much like improving the HE organization. For this very reason, Hill (1992) argued that leadership is a vital dimension to consider when assessing technical professionals. Leadership is important for technology adoption in the HE context (Keengwe et al., 2009), an important component of any IT-enabled change. TL would help with gaining employee commitment to change since employees would be considered in the process, influenced individually to become motivated to perform in the new way of working, and stimulated by the challenge.

While it has been argued that CIOs widely practice TL because it enables organizational transformation (McLean \& Smits, 2014), the HE context faces additional barriers. While TL practices have been found to be high among IT executives in HE, IT employees do not consider the climate to be conducive to innovation (Katz \& Salaway, 2004). The additional barriers faced in HE limit the transformational change that IT can create. Considering that HE context limits the ability of TL to create an innovative environment for IT, we must seek out another concept that mediates the relationship. IT-enabled change and improvements require extensive coordination and collaboration at all levels of the organization which both necessitates and engenders senior executive support from non-IT management (Campbell et al., 2005). IT units in the HE context can expect that their environments will only be transformative if their innovative efforts are supported by the high ranking members of both the academic and administrative sides of the institution. Additionally, IT must have collaborative and synergistic (Nevo \& Wade, 2010) relationships with partners throughout the institution. Consequently, we propose the following propositions for future empirical studies to further explore this phenomenon:

Proposition 1: The impact of TL on innovation in HE context is mediated by the extent of collaborative relationships IT has with the rest of the institution.

Proposition 2: The impact of TL on innovation in the HE context is mediated by the amount of top management support IT receives, both from the academic and administrative segments of the institution.

\section{Implications for TQM}

Much of the focus throughout this paper has been on collaboration in one form or another. The HE problems of the $21^{\text {st }}$ century are too big for any one person to solve alone. For nearly 30 years, TL has been identified as important for TQM success.

Zairi (1991) argued that TQM is a bottom-up activity that is enabled by modern leadership's emphasis on participatory decision-making and employee involvement. He further argued that 
charismatic leadership, the idealized influence and inspirational motivation dimensions of TL, is important for gaining commitment to TQM. Similarly, when analyzing a series of cases, Zairi (1994) identified several factors important for success in TQM implementation, including, setting and communicating a vision, recognizing people as assets, developing a process-based culture, developing partnerships, and engaging in internal leader development. Setting and communicating a vision is a component of both charismatic leadership dimensions. Individualized consideration can only occur once people are recognized as valuable assets. Intellectual stimulation focuses on helping followers to constantly reexamine the methods and processes we use at work (Bass \& Avolio, 1990), asking them to focus on the means we use to achieve ends. Inspirational motivation does not apply only to followers-TL leaders also develop partnerships to attain their visions of the future. And, finally, if TL can show the way to a more participative and process-oriented workplace, that will develop a pipeline of future leaders who follow those same behaviors.

IT leadership is directly involved in three of Deming's 14 points for management. Instituting leadership can be accomplished from the IT perspective by the collaborative behaviors already identified as important. The goal of IT is to help people, machines, and processes in our institutions do better work. This is accomplished by automating processes, providing additional information for decision-making, and creating better tools for connecting the people in and outside of our institutions. A participative and collaborative set of IT leaders will, by forming a diverse set of relationships, help individuals understand how IT can help drive quality in their departments.

Driving out fear and breaking down barriers are highly interrelated because they both rely on interdepartmental communication. Effective IT leadership must create synergistic relationships with non-IT units because IT's functions directly impact everyone except for IT. The only way that IT is affected by their work is the type of skills and expertise required to develop and maintain solutions. The solutions change the relationship our institution's stakeholders have with us. Specifically, IT changes the way employees work, suppliers coordinate with us, and how students apply for and study at our institutions. Learning management systems are nearly universal, demand for online courses and degrees continues to increase, and most students manage their administrative relationships (e.g., tuition payments, class scheduling, transcript requests) with the university through online systems. Breaking down barriers is necessary to drive out fear, and the IT units in our universities are uniquely positioned to accomplish these changes.

\section{Conclusion}

IT leadership, especially that which fits the mold of TL, is uniquely positioned to help HE improve quality. The unique position of the IT function provides them cross-departmental vision that is difficult to find elsewhere. Our HE institutions should take efforts to ensure that IT leadership is involved in the design and implementation of quality initiatives. Researchers should examine the impact of effective leadership not just of whoever is managing the initiatives, but they must also investigate how leadership from key IT employees can help those initiatives succeed. Future research should examine the impact that TL leadership within IT has on HE TQM efforts. Many of the necessary leadership behaviors identified as important for TQM may be fulfilled by transformational IT leaders. 


\section{References}

Bass, B.M. \& Avolio, B.J. (1990), Developing transformational leadership: 1992 and beyond, Journal of European Industrial Training, Vol.14, No.5, pp. 21-27.

doi:10.1108/03090599010135122

Bhatt, G.D., Grover, V., \& Grover, V. (2005), Types of information technology capabilities and their role in competitive advantage: An empirical study, Journal of Management Information Systems, Vol.22, No.2, pp. 253-277.

Bolden, R., Petrov, G., \& Gosling, J. (2008), Tensions in higher education leadership: Toward a multi-level model of leadership practice, Higher Education Quarterly, Vol.62, No.4, pp. 358-376.

Day, D.V., Fleenor, J.W., Atwater, L.E., Sturm, R.E., \& McKee, R. A. (2014), Advances in leader and leadership development: A review of 25 years of research and theory, The Leadership Quarterly, Vol.25, No.1, pp. 63-82. doi: 10.1016/j.leaqua.2013.11.004

Fullan, M., \& Scott, G. (2009), Turnaround leadership for higher education, John Wiley \& Sons.

Hickman, L. \& Akdere, M. (2017), Integrated review of stakeholder theory: Implications for technology adoption and training, in Refereed Proceedings of the 2017 Academy of Human Resource Development International Research Conference in the Americas.

Hill, R.B. (1992), Dual career paths: Recognizing the technical contributor, Journal of Compensation and Benefits, Vol.4, pp. 10-16.

Kanji, G.K. (1990), Total quality management: the second industrial revolution, Total Quality Management, Vol.1, No.1, pp. 3-12.

Katz, R.N. \& Salaway, G. (2004), Information technology leadership in higher education: The condition of the community, EDUCAUSE Center for Applied Research (White Paper).

Keengwe, J., Kidd, T., \& Kyei-Blankson, L. (2009), Faculty and technology: Implications for faculty training and technology leadership, Journal of Science Education and Technology, Vol.18, No.1, pp. 23-28. doi: 10.1007/s10956-008-9126-2

Kezar, A.J., Carducci, R., \& Contreras-McGavin, M. (2006), Rethinking the" L" word in higher education: The revolution of research on leadership: ASHE higher education report, John Wiley \& Sons.

Leih, S. \& Teece, D. (2016), Campus leadership and the entrepreneurial university: A dynamic capabilities perspective, Academy of Management Perspectives, Vol.30, No.2, pp. 182-210. doi: 10.5465/amp.2015.0022

McLean, E.R. \& Smits, S.J. (2014), Management, leadership, and the roles of the CIO, International Leadership Journal, Vol.6, No.1, pp. 3-22.

Padró, F. F. (2010), A leadership model for higher education quality, in Nair \& Webster (Eds.), Leadership and Management of Quality in Higher Education, Elsevier. 
Reich, B. H. \& Benbasat, I. (2000), Factors that influence the social dimension of alignment between business executives and information technology objectives, MIS Quarterly, Vol.24, No.1, pp. 81-113.

Rowold, J., Borgmann, L., \& Bormann, K. (2014), Which leadership constructs are important for predicting job satisfaction, affective commitment, and perceived job performance in profit versus nonprofit organizations? Nonprofit Management \& Leadership, Vol.25, No.2, pp. 147-164.

Zairi, M. (1991), Total Quality Management for Engineers, Woodhead: Cambridge, England. doi: 10.1016/B978-1-85573-024-3/50002-8

Zairi, M. (1994), Leadership in TQM implementations: Some case examples, The TQM Magazine, Vol.6, No.6, pp. 9-16. doi: 10.1108/09544789410073586 